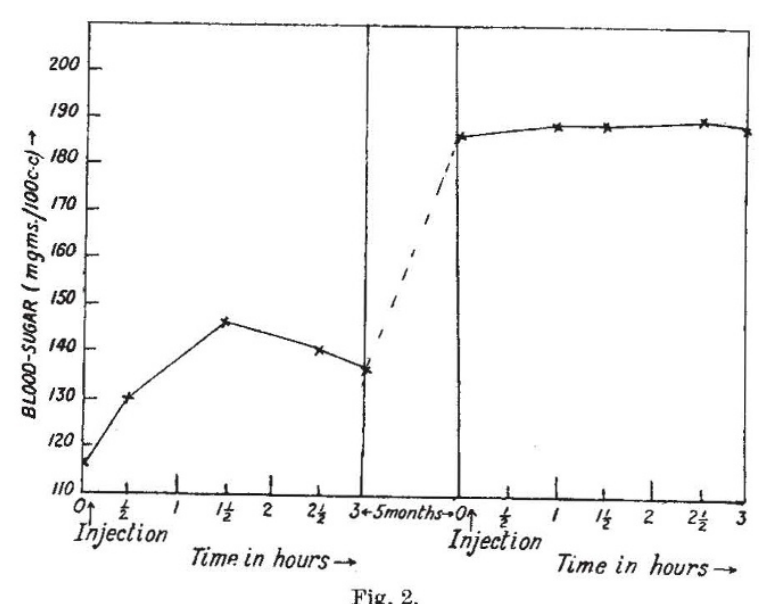

eighteen hours. The experiment was repeated for three days in succession on the same rabbits. The nature of change of blood sugar (average from two animals), during the period of experiment, is represented graphically in Fig. 1. It will be seen that in all cases the initial concentration of fasting-sugar on the third day is definitely higher than that on the first day and the nature of the curve is greatly changed. It is also interesting to record that when the set of animals receiving ethyl acetoacetate for three days was allowed to rest for about one month and the experiment repeated, the fasting blood sugar level was found to be lower than that obtained initially (that is, one month before) and a far greater hyperglycæmic effect was observed on injection of the same substance. This lowering of blood sugar level may indicate the mechanism of natural adjustment, possibly by causing hypersecretion of internal insulin. Two rabbits (male) were then injected daily, beginning with $10.0 \mathrm{mgm}$. of $\beta$-hydroxy-butyric acid and gradually increasing to $400.0 \mathrm{mgm}$. and the blood sugar curves of the animals were obtained on the very first day of injection and after the injections were continued for 150 days. The initial blood sugar value after such period of injection was found to be very high $(187.0 \mathrm{mgm}$. as against $116.0 \mathrm{mgm}$. recorded on the first day) and the nature of the curve (Fig. 2) was found to be greatly changed. This curve was almost a straight one, indicating severe damage to the insulin-secreting mechanism.

It may be suggested that these intermediary fat degradation products might first stimulate the pancreatic cells, which gradually become fatigued through excessive work, possibly through lesions of these cells in the long run. Further investigations which are in progress may throw more light on the matter.

Our best thanks are due to Prof. J. K. Chowdhury and Prof. B. C. Guha for their kind interest in this work.

M. C. Nath.

H. D. Brahmachari.

Physiological Section, Chemical Laboratory, University of Dacca. July 11.

${ }^{1}$ Best, C. H., Campbell, J., Haist, R. E., and Home, A. W., J. Physiol. 101, 17 (1943).

${ }^{2}$ Dunn, J. S., McLetchie, N. G. B., and Sheehan, H. L., Lancet, i, 484 (1943).

3 Dunn, J. S., McLetchie, N. G. B., Lancet, ii, 384 (1943).

- Adams, S. F., J. Nutrition, 1, 339 (1929).

- Joslin, E. P., New Eng. J. Med., 209, 519 (1933).

${ }^{6} \mathrm{E}$ a agedorn and Jensen, Biochem. Z., 135, 46 (1923).

\section{Toxicity to Flies of Derivatives of Eugenol and Cis- and Trans- Isoeugenol}

IT appears that any modification in the pentadienyl side-chain of the pyrethrin molecules induces a profound depression in the insecticidal activity ${ }^{1}$. Although the distribution of the double bonds in the side-chain of pyrethrolone is not yet fully established ${ }^{2}$, there seems to be little doubt that there is either a terminal $=\mathrm{CHCH}_{3}$ grouping or-less probably-the $=\mathrm{CH}_{2}$ group. Allyl phenols have been found to possess insecticidal properties ${ }^{3}$, and it appeared of interest to compare the toxicity in fly sprays of corresponding derivatives of the isomeric phenols eugenol (which contains the allyl grouping) and iso. eugenol (containing the propenyl grouping).

The initial tests showed that when sprayed against flies under exactly comparable conditions in kerosine or kerosine-acetone solution alone, or as adjuvants to the pyrethrins, compounds such as ethers of eugenol were usually more effective than solutions of the corresponding isoeugenol derivatives; but some of the results led to comparison of the cisand trans- forms of the compounds derived from isoeugenol. It was then found that solutions of the cis- forms of the isoeugenol compounds approached the toxicity to houseflies shown by solutions of the corresponding eugenol compounds, whereas the trans. forms were noticeably less toxic in solution alone and when included with small quantities of pyrethrins.

This observation appears to be of some interest in view of the fact that comparison of the effect, as pyrethrin synergists of sesamin, of isosesamin and asarinin against houseflies indicated ${ }^{4}$ that the nature of the substituents on the benzene ring was the determining factor on the synergistic action of this class of compound, spatial configuration being of little or no importance.

The preparation and physical properties of the pure cis- and trans-isoeugenol derivatives employed will be described elsewhere.

\section{Stafford Allen and Sons, Ltd.,}

\section{T. F. WEST.} London, N.1.

${ }^{2}$ West, T. F., Nature, 152, 660 (1943).

${ }^{2}$ Gillam, A. E., and West, T. F., J. Chem. Soc., 671 (1942); 49 (1944). West, T. F., J. Chem. Soc., 51 and 239 (1944). La Forge, F. B., and Acree, F., J. Org. Chem., 7,418 (1942). Cf. TaForge, F. B., and Barthel, W. F., J. Org. Chem., 9, 242 (1944).

${ }^{3}$ Harvill, E. K., and Arthur, J. M., Contrib. Boyce Thompson Inst., $13,(2), 79$ (1943).

${ }^{4}$ Haller, H. L., LaForge, F. B., and Sullivan, W. N., J. Econ. Ent. 35,247 (1942). Cf. Parkin. A. E., and Green, A. A., Nature, 154 16 (1944).

\section{Function of Plant Vacuoles}

Previously $^{1}$, I put forward the view that pinkish vacuoles are receptacles of enzymes for synthesis of various food reserves in plants, lower as well as higher ; in support of this I produced evidence of synthesis of food reserves around the pinkish vacuoles of pyrenoids in Spirogyra and of synthesis of oil drops around pyrenoids in two diatoms. Additional evidence in favour of the view that pinkish vacuoles are receptacles of enzymes is now brought forward from two sources: (1) synthesis experiments ; (2) plasmolysis experiments, in some fungi.

By growing fungi (Polyporus durus and Phomopsis sp.) in fatty acids and glycerine medium, the first formation of oil drops was noticed around the vacuoles in the course of two days, and by growing them in 